\section{Additional Contacts}

Full-time work does not necessarily mean that one's duties are all performed at one centre. There is much to be said for having one main base and a limited contact with one or two other hospitals. It is advantageous to see how other hospitals function, and in certain specialties it is necessary to draw on a wider field than can be supplied by one regional hospital. Much intellectual stimulus may also be derived from additional contacts, particularly with academic centres. Most of my clinical work is undertaken at the Central Middlesex Hospital, but in addition I act as consultant in gastro-enterology to the Postgraduate Medical School and to St. Mark's Hospital.

For those who have become fairly well established. whether they are in part-time or full-time practice, there comes a time when their programme is completely full and bulges into the lunch-time, evenings, and week-ends. It is unfortunately well known, particularly to chairmen of committees, that only busy people have time to undertake extra duties and additional responsibilities. At this point two steps are necessary. One must cultivate the extraordinarily difficult art of declining pressing invitations which may carry great prestige but which may leave insufficient time for basic routine work. It is also necessary to organize occasional work breaks and to take oneself off routine work for a short time to enable one either to write up past work or to plan ahead. The majority of my own papers have been written while on holiday, but this is fundamentally unsound, and it should be better recognized that those in senior responsible positions need intermittent short periods away from routine work to enable them to maintain their special studies in good perspective.

\section{A Landmark}

At the time of the introduction of the N.H.S. Act one was forcibly reminded in the discussions at that time that the conditions of service for full-time staff were essentially dependent on the professional success of their part-time colleagues, which alone saved them from the most mediocre of Treasury scales. Those who advocate universal full-time hospital appointments would do well to remember this elementary fact, and also that it is far better to enable all types to find openings suited to their particular temperaments. It is likely that under the N.H.S. there will be a considerable extension of full-time appointments, not only for auxiliary branches but also for the major specialties.* In his Linacre Lecture, in 1940,. Topley recalled the sudden acceleration of the growth of science in the nineteenth century, which was due to a new class of salaried professional scientists. He expressed no doubt that the same stimulus applied to clinical science would produce the same results. Indeed, that it has already done so can be seen from the records of the professorial units and the special M.R.C. centres. I have no doubt that the extension of full-time work in regional hospitals will in due course be regarded as another landmark in the development of the hospital services of this country.

\section{REFERENCE}

Topley, W. W. C. (1940). Authority, Observation, and Experiment in Medicine. Cambridge Univ. Press.

*In a recent reply to a question in the House of Commons the Minister of Health stated that there were about 1,500 whole-time and about 4,100 part-time consultants working under the National Health Service.

\section{THE PROFESSOR IN THE LABORATORY}

BY

\author{
R. J. V. PULVERTAFT, M.D., F.R.C.P. \\ Professor of Clinical Pathology, Westminster Hospital \\ School of Medicine
}

I could not have chosen to be a clinical pathologist, for when I qualified there was no such title. A character in one of Molière's plays found, to his surprise, that he had been writing prose for years; and I must have been a clinical pathologist for ten years before I realized that, for better or worse, such was my profession.

Laboratory medicine has always been the province of two classes of men since first an attempt was made to replace or reinforce the intuitional dogmatism of the pure physician by cold and often unpalatable facts. In my hospital, for example, it was a physician, Dr. Hebb, whose wide reading and foresight led to the institution of a hospital laboratory. I am but third in the hierarchy, and I inherited as chief technician Mr. F. Chopping, who was the first hospital technician appointed.

But medicine owes a great deal to men who, like Pasteur and the great German pathologists, studied the phenomena of disease as a pure science. Both classes still persist, and perhaps always will. The physicians and surgeons who could afford to be ignorant of the scientific basis of their profession have now, at long last, largely disappeared, and no laboratory worker attached to a hospital can to-day pretend, as one famous London figure did in my youth, that the hospital existed to provide him with material. There remain, however, in the laboratory men whose interest brings them for most of the day to the bedside, and others to whom the universe of the microscope and test-tube is sufficiently wide.

\section{My Way to the Laboratory}

How, then, did I find my way to a hospital laboratory? The first step came when I was given a microscope as a boy, in an age when biology had taken one of those amazing mutational advances which favours in turn each branch of science, and which to-day has smiled on atomic physics. It has never since occurred to me to stop looking down a microscope. My second instrument was lent to me by Sir Arthur Shipley, Master of Christ's, Cambridge, whom I met by accident at an aerodrome in the 1914-18 war. "You will need it," he said : "war is so very boring." At school, however, I read classics. Cambridge, and Sir Gowland Hopkins, first gave me a glimpse of the delight of asking a question of Nature and watching breathlessly for her reply. I read medicine because I had spent years in the pursuit of destruction and hoped for a constructive occupation. I cannot, however, recall any advice given me by any college official. My tutor and I respected each other's privacy. Sir Gowland Hopkins, it is true, took it for granted that I should work in a laboratory- " But take a year off and write poetry," he cautioned me ; " no one should take up research without a background of creative endeavour in another field." I loved Cambridge dearly. No one, I felt, tried to woo me to any creed; but there was a completely universal sincerity to 
try to teach how the closest possible approximation to truth may be attained.

I went to my teaching hospital by accident, because it was on my route to Waterloo Station; but there I found Jobn Mellanby, professor of physiology, who for many years guided me in every step and let me loose in his laboratory. I was not much impressed by consultant medicine and surgery. Surgery seemed to me too often a confession of failure, and a technical exercise without statistical background ; and I could never bring myself to believe that the most impressive diagnosis, even when enunciated by the most dapper of physicians, was of much value if the evidence in support of it was a bit shaky.

\section{Growth of Clinical Pathology}

I met, however, S. C. Dyke, who ran a laboratory for Cuthbert Wallace and Hugh Maclean. This robust trio also ran a civil war with the professor of pathology, who quite understandably resented an insubordinate laboratory service in his hospital. It was Dyke who later founded the Association of Clinical Pathologists. At his feet I first learned that one could be a doctor (I seemed to be committed to that) and still try to keep to facts-and it was Dyke that I followed a year or two later as unit pathologist.

This, however, was a complete accident. On qualifying $I$ applied for a post'in Kenya, where $I$ hoped to do tropical medicine. While I waited for an appointment, a locum was needed in Harrison's V.D. laboratory, and I took it. It was another " rogue" laboratory, and again anathema to the professor ; but Osmond taught me how to use a pipette and how to recognize a bacillus-and there is no more rigid laboratory discipline than the Wassermann test.

Soon Dyke left, and again I sat in for a while. But I never left for Africa-at least not for another twenty years. Cuthbert Wallace was a grand chief, but as the laboratory was excommunicated, or perhaps convicted of Titoism, I got little instruction in pathology from the professor. Mellanby, however, took his place, so far as I was concerned, very happily. I am quite sure that no medical student and no pathological laboratory can afford to be without daily contact with a physiologist.

The rest was inevitable. Whether or not there is always room on the top, it is only the bottom rung of the ladder that needs finding. And there isn't such a crowd there as one might think. But then my ladder had no label. Pathologists in those days were very badly paid ; I kept myself mainly by journalism, and my wife, whom I married young, also had a salaried job. But I do not think that any part of my career was determined by financial considerations. I had plenty to live on-indeed, lived far better in those days than now.

Our status among our clinical colleagues was poor. We had no votes on committees, and often enough met with arrogance and even, at times, with discourtesy ; and we reciprocated. As the only salaried hospital doctors we ranked as professionals; and these were days when socially the size of cars was more important than intellectual calibre. To-day clinical pathologists are equal in pay and status with those in every other branch of the profession. Most of the important advances in medicine have come from the laboratory; the clinical pathologist has of course done less to advance medicine than the physiologist and the pure research worker, but he has the joy of introducing and testing out each new discovery.

\section{Present Conditions}

A new spirit reigns in medicine to-day; the services of the clinical pathologist are sought, not resented; in the best hospitals the best physicians and surgeons are most often in the laboratory, and many of the most distinguished men have spent a year or more there. It is an expanding service, and for some years to come there should be room for the right kind of recruit.

My great fear is that the new status of the clinical pathologist may attract the wrong kind of man; at least the poor financial rewards of clinical pathology in the past ensured that those who took it up were not fortunehunters. It is to be hoped, also, that the shortage of clinical pathologists, caused in part by the poor salaries, may not lead to the appointment of inferior candidates.

Finally, laboratory-minded men and women should realize that clinical pathology combines with the direct service to sick humanity the delights of an exact science and the infinite variety of all biological learning. There is, and I hope always will be, time, staff, and equipment enough for those who wish to initiate new knowledge.

Pure research is a hard and thankless master ; many a good heart has been broken in its service. But the modern student should not forget that clinical pathology is not the only laboratory biological science; he should try to find out what the pharmacologist, the physiologist, the pure bacteriologist, and the biochemist are doing, and where they are doing it. A planned career, it is true, is a dull affair ; opportunism is the spice of life. Still, one might perhaps spend a day or two finding out how many delightful ways there are of earning one's keep in a laboratory.

In the clinical laboratory the pathologist is part of a great unit, sharing detailed interests, sharing too in the prolongation of useful life and the alleviation of unnecessary pain, while pursuing as his major interest branches of biology as fascinating as any, and so varied that any one of them may, if he so chooses, absorb all his interests. But he must, perforce, curb his imagination, and stick closely to the application of established methods rather than to new improvisations. For many these restraints may be galling; and for them pure science, which serves posterity and humanity rather than the present and the unit, will be the happier adventure.

News about medical standards in Russia was given in London recently by two doctors who have just returned from a visit to the U.S.S.R. The chairman of the delegation from the Society for Cultural Relations with the U.S.S.R., Dr. Horace Joules, said that he had been much impressed by the treatment given in the polyclinics and by the importance attached to preventive medicine. Doctors have to spend eight hours a month teaching preventive medicine to the public or to their patients in hospital. Russian doctors had been convinced by the evidence provided by British and American doctors that smoking increases the incidence of carcinoma of the lung (see British Medical Journal, 1950, 2, 739 and 767), and without doing any research of their own into this problem they began to publicize this fact a year ago, and it is estimated that the consumption of tobacco has already fallen by $10 \%$. An intense drive is being made to eradicate tuberculosis, and all children are vaccinated with B.C.G.; miners and industrial workers have chest radiographs taken frequently. Private medical practice does still exist in Russia, but the number of doctors working outside. the polyclinics is decreasing. There is no shortage of doctors, and Dr. I. C. Gilliland said that the doctors waited for the patients rather than the other way round. 